\title{
Non Descent Vaginal Hysterectomy: A Rational Surgical Approach
}

\author{
ARIFAAKTER ZAHAN ${ }^{1}$, KH.SHAHNEWAZ $^{2}$, FAHMIDA KHAN ${ }^{3}$, UMMAY SALMA ${ }^{4}$
}

\begin{abstract}
:
Objective(s): The aim of the study wasto evaluate the safety and feasibility of non-descent vaginal hysterectomy in advancing gynaecological practice.

Materials and methods: This prospective observational study was conducted from $1^{\text {st }} \mathrm{July}$ 2013 to $31^{\text {st }}$ June 2014 in Obstetrics and Gynaecology Department of Kumudini Women's Medical College \& Hospital, Mirzapur, Tangail.

Fifty patients who needed hysterectomy for benign gynaecological disorders and who had no descent of uterus or vagina were the target population for this study.

Main outcome measures were i) difficulty of operation, ii) procedures for overcoming the difficulties, iii) switch over to abdominal route, iv) time taken to complete the operation, v) blood loss during operation vi) need of blood transfusion and vii) postsurgical hospital stay.

Results: In all (100\%) cases vaginal hysterectomy was completed successfully. Commonest age group (46\%) was between 41-45 years. All patients were parous. Size of the uterus was less then 8 wks in 21 cases, 8wks to 12 wks in 27 cases and more than 12 wks in 02 cases. Commonest indication was dysfunctional uterine bleeding (DUB) (44\%). Mean duration of surgery was $50.5 \pm 5.46$ minutes. Mean blood loss was $100 \pm 22.43 \mathrm{ml}$. Blood transfusion was required in four cases. Average duration of hospital stay was $3.1 \pm 1.2$ days. Complications were minimum which included, bladder injury, UTI and Vault infection.
\end{abstract}

Conclusions: In properly selected cases non-descent vaginal hysterectomy is safe, feasible and patient friendly.

Introduction:

Hysterectomy is the most common major gynaecological surgery. It can be done by abdominal or vaginal route. In abdominal route laparoscopy assisted vaginal hysterectomy (LAVH), although gaining more popularity is associated with higher cost $^{1}$, longer duration of operation, and need for specially trained personnel. On the other hand, non descent vaginal hysterectomy is associated with less morbidity, lower health care costs, lesser hospital stay, minimal complications and better patient satisfaction compared to laparoscopic techniques ${ }^{2}$. Therefore, there is a need for expanding the indication for vaginal hysterectomy $(\mathrm{VH})$ rather than restricting it to the conventional indication of uterovaginal prolapse ${ }^{3}$. Usual limitation of vaginal hysterectomy in non-descent uterus is its size but now with larger sizes, hysterectomy can be facilitated by bisection, myomectomy wedge debulking and morcellation ${ }^{4}$.

The aim of this study was to explore the safety and feasibility of non-descent vaginal hysterectomy in some selected cases

\section{Materials and methods:}

This prospective observational study was conducted from July 2013 to June 2014 in Obstertrics and Gynaecology Department of Kumudini Women's Medical College \& Hospital, Mirzapur, Tangail. Fifty patients, who needed hysterectomy for benign gynaecological disorders and who had no descent of uterus or vagina were the target population for this

1. Associate Professor, Dept of Obst \& Gynae, Kumudini Women's Medical College \& Hospital

2. Professor, Dept of Obst \& Gynae, Kumudini Women's Medical College \& Hospital

3. Associate Professor, Dept. of Obstetrics \& Gynaecology, Shaheed Suhrawardy Medical College, Dhaka

4. Register, Dept of Obst \& Gynae, Kumudini Women's Medical College \& Hospital 
study. Selection criteria for non descent vaginal hysterectomy (NDVH) were i) uterine size not exceeding 14 weeks of gravid uterus (by clinical judgment), ii) adequate vaginal access with good uterine mobility and ii) no previous pelvic surgery including caesarean section. Exclusion criteria included uterus with restricted mobility, suspicion of malignancy and complex adnexal masses. Consent for conversion of procedure to abdominal hysterectomy (if needed) was taken. Pap smear for cytology in all cases and diagnostic D\&C was carried out in suspected cases. All cases were re-assessed in operating theater after the patient was anesthetized to confirm the size, mobility of uterus, vaginal accessibility and laxity of pelvic muscles. Vaginal hysterectomy was considered successful if it was not abandoned or converted to abdominal route. In bigger uterus morcellation techniques like uterine bisection, debulking, myomectomy or combinations of these were performed when required. Data regarding age, parity, uterine size, indications, estimated blood loss, length of operation, complications, adjuvant procedures, clinical outcome and hospital stay were recorded. Estimated blood loss was calculated by deducting previously weighted gauze and mop from blood socked weighted gauze mop and transfer the weight in milliliter $(1 \mathrm{oz}=30 \mathrm{ml})$. All patients received prophylactic antibiotics for 5 days. Post-operative Foley catheter was kept in all cases for 12 to 24 hours. All patients were followed from time of admission to time of discharge and 2 weeks and 4 weeks thereafter.

\section{Operative Technique:}

All cases were done under spinal anesthesia. After cleaning and draping, cervix was held with volsellum. Before making the incision adrenaline diluted in normal saline was injected in the uterus in order to minimize blood loss. Circumferential incision was made around the cervix, pubo-vesico-cervical ligament was cut and bladder mobilized upwards. Both anterior and posterior pouches were opened one after another. Uterosacral and cardinal ligaments were clamped, cut and ligated. Clamping of uterine vessels was done bilaterally. Next in big sized uterus morcellation techniques like uterine bisection, debulking, myomectomy or combinations of these were performed when required. In case of fibroid with big sized uterus bisection was done after ligating the uterine arteries and myomectomy was done to ease limitation of space for further proceedings. In total hysterectomy, last clamp was on uterine cornu containing round ligament, ovarian ligament and medial part of fallopian tube. To remove ovaries, round ligament was clamped separately followed by clamping of infundibulopelvic ligament. Finally uterus was removed. All patients received 5 days of prophylactic antibiotics. Vaginal pack and postoperative catheterization were kept for $24 \mathrm{hrs}$. Main outcome measures were i) difficulty of operation, ii) procedures for overcoming the difficulties, iii) switch over to abdominal route, iv) time taken to complete the operation, v) blood loss during operation vi) need of blood transfusion and vii) postsurgical hospital stay.

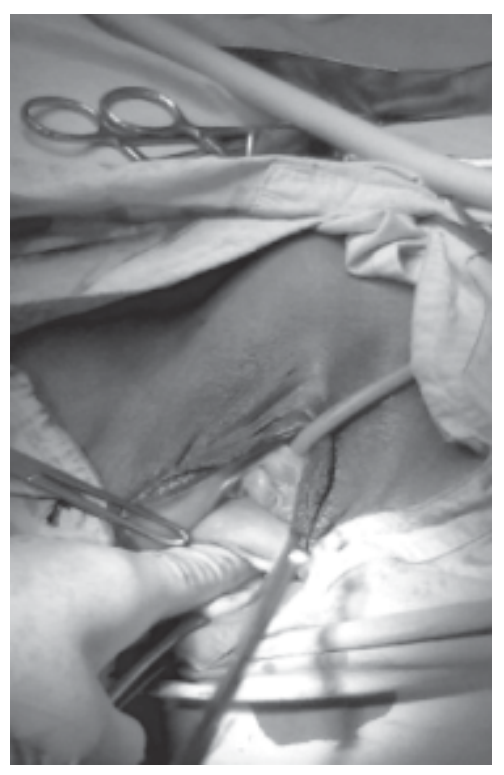

Fig .-1: Holding

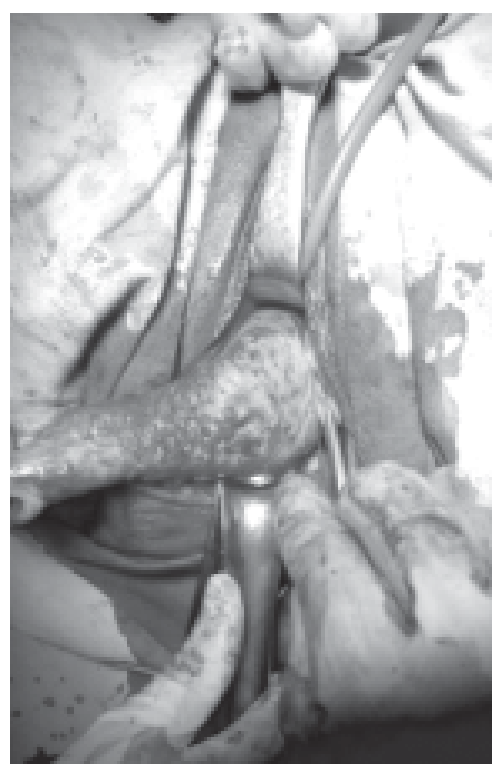

Fig .-2: Bisecting the uterus the lips of cervix 


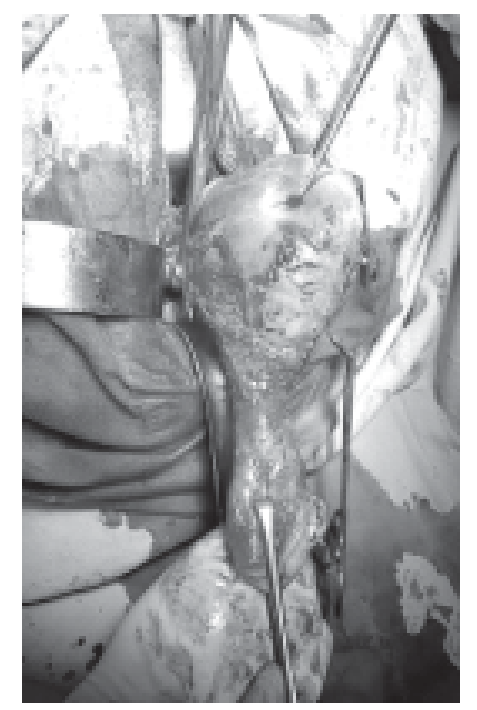

Fig .-3: $2^{\text {nd }}$ clamp completed

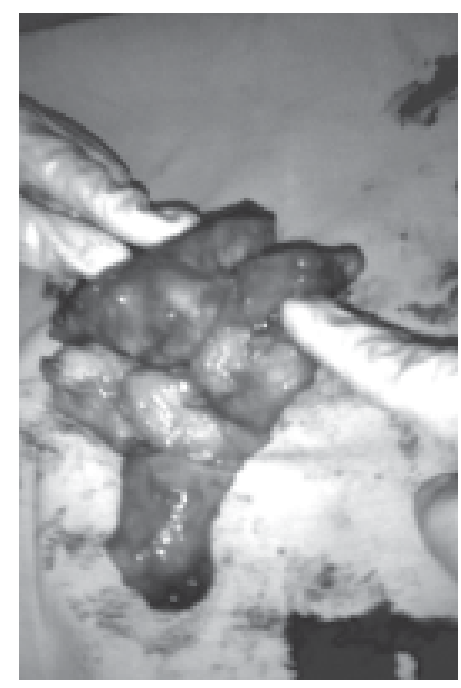

Fig .-4: Giving $3^{\text {rd }}$ clamp

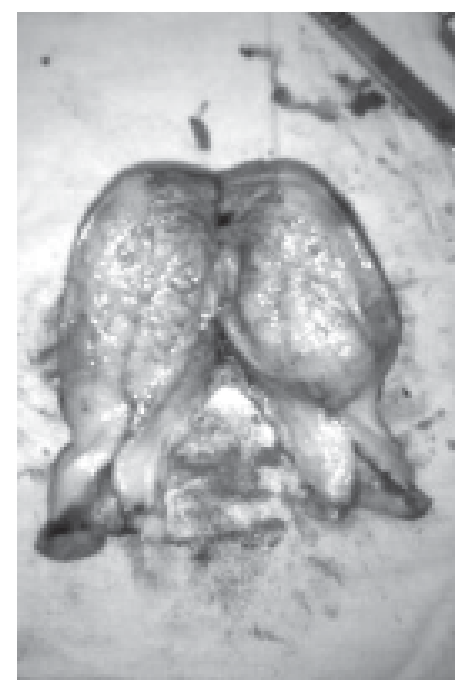

Fig .-5: After removal of piecemeal uterus

\section{Results}

Table 1 shows the characteristics of patients. Most of the patients were multiparous women, which is favorable for vaginal hysterectomy. Common indication was DUB (44\%) where size of the uterus was not bigger. In majority (54\%) cases size of the uterus was within 8-12 weeks size and in $42 \%$ cases it was less than 8 weeks sized. Regarding outcome of the procedure we operated all cases successfully through vaginal route though in few (42\%) cases there was some difficulties to remove the uterus. Difficulties were overcome by bisection of the uterus in $22 \%$ cases, myomectomy in $14 \%$ cases and slicing and debulking in $06 \%$ cases (Table 2). There were minor complications of the procedures but in one case bladder was injured which was repaired immediately. Mean time taken for operation was $50.5 \pm 18.23$ minutes and range was 35-100 minutes. There was no significant blood loss during the procedure. Mean hospital stay was $3.1 \pm .932$ days. (Table 2 ). Figures shown the steps of the operation.

Table-I Patients characteristics

\begin{tabular}{lcc}
\hline Characteristics & Mean & \pm SD \\
\hline Age (Yrs) & 42.72 & \pm 5.22 \\
& $\mathrm{~N}$ & $\%$ \\
Parity & & \\
1 & 4 & 08 \\
2 & 27 & 54 \\
3 & 15 & 30 \\
4 & 4 & 08 \\
Indications & & \\
Fibroid uterus & 15 & 30 \\
DUB & 22 & 44 \\
Adenomyosis & 05 & 10 \\
Cervical polyp & 05 & 10 \\
Myomatous polyo & 03 & 06 \\
Uterine size & & \\
Normal to <8 weeks & 21 & 42 \\
8-12 weeks & 27 & 54 \\
$>$ 12 weeks & 02 & 04 \\
\hline
\end{tabular}


Table-II

Outcome of Surgery

\begin{tabular}{lcc}
\hline Parameters & $\mathrm{N}$ & $\%$ \\
\hline Completed Vaginally & 50 & 100 \\
Difficulties during procedure & 21 & 42 \\
Difficulties overcomed by & & \\
$\quad$ Bisection & 11 & 22 \\
$\quad$ Myomectomy & 07 & 1406 \\
$\quad$ Slicing and debulking & 03 & \\
Complications & & \\
$\quad$ Bladder injury & 01 & 02 \\
$\quad$ Vaginal cuff infection & 02 & 04 \\
$\quad$ Secondary haemorrhage & 03 & 06 \\
$\quad$ UTI & 04 & 08 \\
Need of blood transfusion & 04 & 08 \\
$\quad$ Mean \pm SD & Range \\
Mean operating time (min) & $50.5 \pm 18.23$ & $35-100$ \\
Mean blood loss (ml) & $100 \pm 10.18$ & $40-150$ \\
Mean hospital stay (day) & $3.1 \pm .932$ & $3-5$ \\
\hline
\end{tabular}

\section{Discussion:}

It is a well-known fact that $70 \%$ to $80 \%$ of hysterectomies are performed by abdominal route and vaginal approach is usually reserved for uterovaginal prolapse ${ }^{5}$.The usual contraindications for vaginal hysterectomy are absence of significant uterovaginal descends, presence of uterine enlargement, adhesions and the need for oophorectomy. With adequate vaginal access and good uterine mobility, vaginal hysterectomy can be easily performed. In our series out of 50 cases selected for NDVH, all cases were completed successfully. No one needed conversion to abdominal hysterectomy and proper selection of the patient may be responsible for that.Though one study shows conversion of the procedure to abdominal hysterectomy for various reasons ${ }^{6}$. In this study majority of the patients were in the age group of 41-45 years and most of them were multiparous, which is comparable to other studies $^{7-12}$. The commonest indication was DUB (44\%) and next common was fibroid uterus (30\%). In other studies fibroid was the commonest one $3,9,10,13$. In our study $82 \%$ patients had only $\mathrm{NDVH}$, $16 \%$ had NDVH with salpigoophrectomy, and $2 \%$ had NDVH with kelly's repair for stress urinary incontinence. This suggests that adnexal pathology (cyst up to $5-6 \mathrm{~cm}$ ) can be dealt vaginally without any complication and urogynaecological surgery can also be performed at same time in $\mathrm{NDVH}^{14}$.In our study none of the cases had abdominal pelvic surgery, 13 had bilateral tubal ligation. Mean blood loss was $100 \pm 10.18 \mathrm{ml}$. It was lesser than that reported in other studies (268-316 ml) ${ }^{8-11}$. Four (08\%) of the patients required blood transfusion, which is same as shown by CREST study. Mean duration of surgery was $50.5 \pm 18.23$ minutes as compared to Goel et al (64 minutes) ${ }^{8}$, Dewan et al (54.5 minutes) ${ }^{9}$, Bharatnur et al (65minutes) (10), and Bhadra (55 minutes) ${ }^{11}$. Same was noted by Seth in his personal series of 5655 cases $^{15,16}$. Usually operating time depends upon skill of the surgeon, size of the uterus and some associated factors like presence of fibroid and adhesions. The length of hospital stay reported by Dorsey $\mathrm{JH}$ et al ${ }^{[17]}$ was 3.5 days. In our series hospital stay was 3.1 days. Difficulties of operation such as dissection of adhesion due to ligation, clamping and removal of large sized uterus were in 21 cases. Debulking was done when the uterine size was more then 8 wks. Among all of large uterus debulking and bisecting of the uterus remained the common technique, which was shown by other study also $^{18}$. Major complications were less due to prior and proper selection of cases. In one case there was urinary bladder injury due to previous adhesion. There were minor complications like UTI and vault infection, which is comparable with other studies also ${ }^{6}$.

In conclusion it can be said that in properly selected cases non-descent vaginal hysterectomy can be performed easily and safely at expert hand, which reduces the patient's trauma and hospital stay. Considering the fact that it does not need to make any extra hole for the procedure, this route should be the choice of hysterectomy in all DUB cases as well as in myoma and adenomyoma if size of the uterus is reasonable. Though comparative study with abdominal hysterectomy and laparoscopic hysterectomy would give a better conclusion, this small observational study proved safety of the procedure.

\section{References:}

1. Meikle SF, Nugent SW, Oleans M. Complications and recovery from laparoscopy assisted vaginal hysterectomy compared with abdominal and vaginal hysterectomy. Obstet Gynecol.1997; 89: 304-11.

2. Ransom SB, Mc Neeley SG, White C,Diamond MP. A cost analysis of endometrial ablation, abdominal hysterectomy, vaginal hysterectomy and laparoscopy - assisted vaginal hysterectomy in the treatment of primary menorrhagia. J Am Assoc GynaecolLaparosc. 1996; 4(1):29-32. 
3. Meikle SF, Nugent EW, Orleans M. Complications and recovery from laparoscopicassisted vaginal hysterectomy compared with abdominal and vaginal hysterectomy. Obstet Gynecol 1997;89:304-11.

4. Unger JB. Vaginal hysterectomy for the women with moderately enlarged uterus weighing 200 to 700 grams.Am J Obstet Gynaecol 1999;180:1337-44.

5. Thomas G.Stovall.Hysterectomy.Berek \& Novak's Gynecology14th Edition. 2007; 22(c): 805.

6. Saha R, Shrestha NS, Thapa M, et al. Nondescent Vaginal Hysterectomy: Safety and Feasibility. NJOG. 2012; 7(2): 14-16.

7. Johnson N, Barlow D, Lethaby A, Tavender E, Curr L,Garry R. Methods of hysterectomy: systematic review and meta-analysis of randomised controlled trials. $\mathrm{BMJ}$ 2005;330:1478.

8. Goel N, Rajaram S Agarwal R, Mehta S (eds) Step by Step Non-Descent vaginal hysterectomy.Delhi: Jaypee Brothers Medical Publishers (P) Ltd. New Delhi, 2010.

9. Dewan R, Agarwal S, Minocha B, Sen SK. Nondescent Vaginal Hysterectomy -An Experience . J Obstet Gynecol Ind .2004;54(4):376-8.

10. Bharatnur S. Comparative study of abdominal versus vaginal hysterectomy in Non-Descent cases. Internet J Gynecol Obstet. 2010; 15(2):1528.
11. Bhadra B, Choudary AP, Tolassaria A, Nupur N. Non-Descent Vaginal hysterectomy (NDVH): Personal experiences in 158 cases. AL Ameen J Med Sci.2011;4(1):23-7.

12. Dicker RC, Greenspan JR, Strauss LT etal. Complications of vaginal and abdominal hysterectomy among women of reproductive age in the United States. Am J Obstet Gynecol. 1982; 144: 841-8.

13. Singh A, Bansal S. Comparative study of morbidity and mortality associated with Nondescent Vaginal hysterectomy based on ultra sonographic determination of uterine volume. IntSurg. 2008;93(2):88-94.

14. Shital T Mehta, Yamini Trivedi, Pratik Bhalodia. Role of non-descent vaginal hysterectomy in advancing gynaecological practice. NHL Journal of Medical Sciences. 2014; 3(1):55-58.

15. Sheth SS. Vaginal hysterectomy.In: PuriR, Malhotra N. eds. Operative Obstetrics and Gynaecology. New Delhi. Jaypeebrother's medical publishers.2009:499-510.

16. Sheth SS, Paghdiwalla K P. In: Saraiya UB, Rao A K, Chateerjee A.eds.Principles and Practice of obstetrics and Gynaecology. $2^{\text {nd }}$ edition. New Delhi. Jaypee brothers medical publishers. 2003

17. Dorsey JH,Steinberg EP,Holtz PM,Clinical indications for hysterectomy route: patient characteristics or physician preference Am J Obstet Gynecol. 1995; 173 (5): 1452-1460.

18. KW Cheung, TC Pun. Vaginal hysterectomies in patients without uterine prolapse: ten-year experienceHong Kong Med J. 2013;19:323-327. 